\title{
THE DAIMPING OFF OF TOBACCO AND ITS CONTROL IN PUERTO RICO
}

\author{
By J. A. B. Nolla, B.S.A., M.S.
}

The paper deals with a very severe disease of tobaceo seedlings in Puerto Rico, two organisms, Pythium debaryanum and Phytopthora Parasitica var. nicotinae having been found to be causal agents.

The symptoms produced by two pathogens are very similar and are mainly of the necrotic type. Small seedlings when affected usually rot completely while larger seedlings may show other symptoms. On the latter, small, lens-shaped or elongated lesions, or large necrotic areas which often eause the girdling of the stems, are evident. Affected seedlings occasionally send out roots above the lesions in an effort to recover. If infected with Pythium debaryanum such seedlings may develop into normal plants when transplanted, but if the lesions are produced by $P$. Parasitica, death takes place within a short time after transplanting. In infections by $P$. Parasitica, a leaf spot is usually part of the symptomological picture.

Of the environmental factors which favor the spread and severity of the disease, probably the most important is moisture; while temperature, not being a very variable factor in Porto Rico, at least below the limits which might hinder the development of the pathogens, seems to be of less significance. When adequate moisture relations are maintained, the disease appears to be equally severe during all seasons of the year. It is maintained that the disease spreads very rapidly and with great severity in thickly sown beds.

The known methods of eradication and protection for this disease and their merits in Puerto Rico are discussed.

The spread of the disease may be checked in some instances of light infection by drenching diseased areas with a 1 to 30 formaldehyde solution, but it is clear that protection can not be afforded by this means when the spores of the fungous agents have been disseminated by surface currents or drainage water prior to the treatment.

For tobacco seed-beds a successful fungicide or soil disinfestant should be of continued action and should either eradicate the pathogens from the soil or protect the seedlings from infection up to the time of transplanting. Formaldehyde and steam disinfestation are effective methods when reinfestation is prevented. Their use in 
Puerto Rico is not practicable because of the high cost of application and because in that island the system of seed-beds is such that reinfestation ean not be prevented.

In experiments under controlled conditions, copper stereate, Uspulun, Bayer dust, copper sulfate, copper flousilicate and acetic acid have proven to be ineffective in controlling the disease. Trials with Corona copper carbonate (about 20 per cent metallic copper) at different rates of application show that fairly satisfactory eradication and protection is afforded with two applications of four grams of the dust, one a week before sowing the seed, the other two weeks after germination. In field trials when the dust is applied after the disease has started, the treatment is ineffective.

Experiments with Bordeaux mixture (4-4-50 and 5-5-50) have proven the effectiveness of this fungicide as a soil disinfestant for damping-off in tobacco. Two applications should be made, one a week before sowing the seed, and another two weeks after germination, the rate of application being one-half gallon of the mixture for every square foot of bed surface.

When copper fungicides are applied to the soil on beds soon after a crop of seedlings has been grown, injury to seedlings of the second crop results. Such injury does not occur when the chemicals are applied to a soil which has not previously grown tobaceo.. The injury results in imperfect germination, and in yellowing, stunting and a defective root system of the seedlings. Such a condition is attributable to indirect action of the copper compounds which may either react with substances excreted into the soil by the seedlings of: the preceding crop, or may affect the soil flora in a deleterious way. A hindrance of the activities and development of the beneficial soil mieroorganisms may cause starvation of the seedlings. 